\title{
RESUMOS DAS DISSERTAÇÕES APRESENTADAS EM 2010, NO PROGRAMA DE PÓS-GRADUAÇÃO EM DESENVOLVIMENTO LOCAL (PPGDL) - MESTRADO ACADÊMICO UNIVERSIDADE CATÓLICA DOM BOSCO - CAMPO GRANDE, MS ${ }^{1}$
}

O Programa de Pós-graduação em Desenvolvimento Local, implantado em 1998, e destaca-se por ser interdisciplinar, tendo como missão "promover, por meio de atividade de ensino, de pesquisa e de extensão, a formação integral, fundamentada nos princípios éticos, cristãos e salesianos, de pessoas comprometidas com a justiça social para que contribuam com o desenvolvimento sustentável".

O Desenvolvimento Local neste programa é entendido como o protagonismo dos atores de um dado território, com apoio de organizações públicas e privadas, na reflexão da realidade vivida para agenciar e coordenar, por meio de processos interativos e cooperativos, os recursos tangíveis e intangíveis originários do local ou de áreas externas, na busca de soluções sustentáveis para os problemas, necessidades e aspirações coletivas, de ordem social, econômica, cultural, política e do ambiente natural.

A relação dos resumos apresentados neste número da Interações - Revista Internacional de Desenvolvimento Local - segue a ordem cronológica das defesas das dissertações, seguidas do título, nome do(a) autor(a), do(a) orientador(a) e data de apresentação perante a banca examinadora. Todos os trabalhos estão disponíveis na Secretaria do Programa de Pós-graduação em Desenvolvimento Local, na Biblioteca Félix Zavattaro, no campus da Universidade Católica Dom Bosco, na cidade de Campo Grande, MS, Brasil e no site do Programa - www.ucdb.br/mestrados/desenvolvimentolocal. Os resumos seguem uma sequência lógica obedecendo à continuação dos resumos publicados na Interações, v. 14, n. Especial, 2013.

143 - Título: A COMUNIDADE DO BAIRRO ZÉ PEREIRA EM CAMPO GRANDE-MS: PONTENCIALIDADES DE DESENVOLVIMENTO LOCAL

Nome: Cleide Regina Pinheiro Martins

Orientador: Dra. Maria Augusta de Castilho

Data da apresentação: 08/02/2010

Resumo: Com o objetivo de proceder ao levantamento das dinâmicas locais que promovem o desenvolvimento endógeno da comunidade do bairro Zé Pereira, localizado em Campo Grande, Mato Grosso do Sul, foi realizada esta pesquisa q ualitativa com uma abordagem fenomenológica. Utilizaram-se seguintes procedimentos: revisão bibliográfica sobre o tema, levantamento de dados estatísticos do local desde o início da divisão do loteamento do bairro há 20 anos realizado pelo Programa de Atendimento a Comunidades de Baixa Renda (PROSANEAR - 1995), levado a efeito, visando proporcionar um conhecimento da realidade socioeconômico do local. O estudo foi baseado também em entrevistas semiestruturadas com moradores do bairro, observações in loco, destacando as características do local, bem como suas potencialidades. A evolução do bairro em seus diversos aspectos permitiu um estudo no inicio de sua fundação (1995) e as potencialidades de desenvolvimento local (2007). No estudo, analisaram-se aspectos sobre escolaridade, religião, profissão, emprego, tipos de residências, dentre outro, em 1995 e o desenvolvimento em 2007, onde se identificaram ações da comunidade em benefício do desenvolvimento local sustentável, com destaque para o artesanato, comércio e lazer.

Palavras-chave: Comunidade. Territorialidade. Desenvolvimento local.

144 - Título: AS RELAÇÕES DE CONFIANÇA EMBASADAS NA PERCEPÇÃO DE RISCOS EM ENTIDADE DE ECONOMIA SOLIDÁRIA

Nome: Irio Ávila Gonçalves

Orientador: Dra. Cleonice Alexandre Le Bourlegat

Data da apresentação: $26 / 04 / 2010$

Resumo: O objetivo deste trabalho é discutir a manutenção das relações de confiança entre os atores das entidades de economia solidária. Para isso utilizamos a metodologia quali-quantitativa do tipo

\footnotetext{
${ }^{1}$ Pesquisa elaborada pelos mestrandos do PPGDL - Luiz Henrique Eloy Amado e Leandro Henrique Araújo Leite, que são bolsistas da CAPES no referido programa.
} 
avaliativa conscientizadora dentro da pesquisa-ação. O sujeito de nossa pesquisa é uma entidade de economia solidária de Porto Alegre que trabalha com produtos de agricultura fa-miliar. O texto apresenta uma discussão conceitual acerca das dimensões do desenvolvimento e da governança local, de suas características e ambientes de controle e risco, demonstrando as diferenças entre os empreendimentos tradicionais e aqueles de características de economia coletiva ou solidária. Descreve-se as relações de confiança formais ou informais como fatores importantes para a manutenção da sua gestão, além de avaliar mais especificamente, o capital relacional entre as entidades de economia solidária de forma comparativa, antes e depois da indicação dos riscos estabelecidas a partir do uso da matriz de risco. Os resultados obtidos demonstram uma mudança de percepção dos atores em relação à confiança interna e na rede, sendo algumas dessas mudanças significativas e outras de manutenção da confiança antes percebida, podendo com essa conscientização contribuir com sustentabilidade das entidades de economia solidária. E, quiçá, robustecer o empreendimento pesquisado a partir do enfren-tamento dos riscos por meio de ações individuais e coletivas que diminuam as fragilidades internas e sistêmicas, potencializando o aumento das relações e a sustentação das atividades de maneira perene, de modo a favorecer o desenvolvimento das localidades produtoras e con-sumidoras, que se materializam no território do Rio Grande do Sul.

Palavras-chave: Confiança. Riscos. Economia Solidária.

\section{5 - Título: COMUNITARIZAÇÃO DO GRUPAMENTO RURAL NO CONTEXTO DO TERRITÓRIO DE “TRÊS BARRAS” DE CAMPO GRANDE-MS}

Nome: Valter Schneider

Orientador: Prof. Dr. Vicente Fideles de Ávila.

Data da apresentação: 29/07/2010

Resumo: A comunidade escolhida para realização do trabalho é o grupamento rural do território de Três Barras da área urbana de Campo Grande - MS. O objetivo focou as principais razões que tem dificultado a citada comunidade a tomar e autogerir iniciativas de efetiva comunitarização, visando seu Desenvolvimento Local de caráter endógeno-emancipatório. O tipo de pesquisa foi a qualitativa descritiva e, classificada com base nos procedimentos técnicos, como estudo de campo. $\mathrm{O}$ trabalho adotou duas formas de abordagens: a primeira pautada por roteiro base, diretamente dialogal com quatro personagens importantes da comunidade, a segunda, com base em entrevistas conduzidas por questionário com questões fechadas, e outras, de natureza qualitativa, mais abertas para ensejar respostas livres. O referencial teórico foi abrangente e envolveu aspectos históricos do Desenvolvimento Local desde a visão européia, latinoamericana, brasileira e, em destaque, a do Mestrado/UCDB. Abordou variáveis indiretas ligadas ao tema, mas o foco principal foi a cultura de hábitos associativos, cooperativos e de empreendedorismo comunitário. Os resultados obtidos demonstraram fenômenos-eixo divergentes que acarretam uma situação de crise, estagnação e apatia da Associação de Moradores e Produtores. Detectou-se a pretensão de alguns associados em criar uma nova ent idade, com finalidade mais específica, congregando somente produtores rurais, para incentivá-los abraçar um grande objetivo a ser escolhido pelos associados. Esta futura associação propõe o envolvimento de novos dirigentes e novas atitudes em projetos com apoio de iniciativas associativistas/cooperativistas, buscando integração com moradores e parceria com a Escola Agrícola local. 146 - Título: CONHECIMENTO E INOVAÇ̃̃O NO ARRANJO PRODUTIVO LOCAL DA CRIAÇÃO
DE AVESTRUZ DE SÃO GABRIEL DO OESTE-MS E DESENVOLVIMENTO LOCAL

Nome: Jayro de Sousa

Orientador: Dra. Cleonice Alexandre Le Bourlegat

Data da apresentação: 31/03/2010

Resumo: São Gabriel do Oeste em Mato Grosso do Sul, situado num ambiente do Cerrado brasileiro, abrigou um grupo de criadores de avestruz desde 1996, frente a oportunidades do comércio internacional. O objetivo geral do presente estudo foi identificar esse Arranjo Produtivo Local da Estrutiocultura, do ponto de vista de sua estruturação e dinâmica de funcionamento, assim como, o modo como vem sendo realizada a aprendizagem desse novo negócio antes desconhecido dos brasileiros e as inovações dela já decorrentes. Numa abordagem sistêmica - em que o olhar se volta para a apreensão das articulações e interdependências estabelecidas entre os atores econômicos e instituições locais - a pesquisa teve caráter exploratório, com busca de dados em fontes primárias e secundárias (questionários e entrevistas). A análise integrada foi de natureza qualitativa e quantitativa. Trata-se de uma atividade recente em todo Brasil e ainda pouco regulamentada, portanto mais facilmente exposta a riscos de comportamentos 
oportunísticos. O mercado nacional foi afetado especialmente pelo chamado golpe da Avestruz Master em 2006, resultando em abandono da atividade por uma grande parte de criadores, além do esfacelamento da cadeia produtiva em franca construção. Em Mato Grosso do Sul, os criadores remanescentes encontramse espalhados. Existe, no entanto, um esforço específico em São Gabriel do Oeste, por parte da empresa pioneira e melhor estruturada do Estado, em construir um Arranjo Produtivo Local, por meio do estímulo à construção de uma rede de terceirização dos serviços de cria e recria e de produção e disseminação de inovações. Palavras-chave: Arranjo produtivo local. Desenvolvimento local. Estrutiocultura. Inovação.

\section{7 - Título: CRIAÇÃO DE OVINOS CONFINADOS PARA PRODUÇÃO DE CARNE, ALIMENTADOS COM RAÇÃO A BASE DE MANDIOCA COMO ALTERNATIVA PARA AGRICULTURA FAMILIAR NO MUNICÍPIO DE CAMPO GRANDE, MS}

Nome: Paulo Henrique Ferreira Yoshihara

Orientador: Profa. Dra. Marney Pascoli Cereda

Data da apresentação: $26 / 04 / 2010$

Resumo: No Brasil, com destaque no estado de São Paulo a agricultura familiar é responsável pela maior parte da produção das culturas alimentícias, mas gera pouca renda, como conseqüência da seleção das atividades e da tecnologia disponível. A pesquisa avaliou a diversificação da produção animal com confinamento de ovinos alimentados com ração a base da planta integral de mandioca para produção de carne, com tecnologia social e inovadora em agricultura familiar no município de Campo Grande, MS. A mandioca é disponível nas propriedades, mas pouco aproveitada como fonte de proteína. O confinamento, embora mais caro que o pasto, permite melhor controle da saúde animal e manejo mais cuidadoso. Tais fatores, em conj unto, podem reduzir a dependência de rações do mercado e aumentar a produtividade animal. Como alternativa para a agricultura familiar, a produção de ovinos, poderá se beneficiar de mão-de-obra disponível para o confinamento, aproveitar o esterco gerado em hort- frutes e pastagens. A planta toda (raízes e ramas com folhas) foi desintegrada e desidratada ao sol com custo de R $\$ 221,00 /$ t. com bom valor nutricional. A ração, elaborada com $40 \%$ de mandioca integral, foi fornecida a ovelha s da raça Santa Inês em confinamento por 56 dias. A produtividade e custos foram estabelecidos. Por se tratar de ração não convencional, mas alternativa, a aceitação foi acompanhada e o comportamento animal (consumo, hidratação, deslocamento, ócio e ruminação) analisado por visão computacional como forma de explicar os resultados. Os resultados mostram que a ração à base de mandioca foi bem aceita e proporcionou maiores ganhos de peso quando comparada a ração comercial. No Município de Campo Grande foi identificado consumo de carne de ovinos ligado à cultura de imigrantes de outros países (sírios, libaneses, árabes) ou nacionais (gaúchos) incluindo os subprodutos (pele, lã) ligados a cultura local (pantaneira), mas esse consumo não se mostrou suficiente para impulsionar o mercado de cordeiros. Face às questões analisadas a criação de ovinos confinados com ração à base de mandioca integral é uma tecnologia apropriada para a agricultura familiar e poderá garantir o consumo próprio com alta conversão a custo compatível, propiciando o abate precoce de ovinos com 8 meses de idade. Não foram identificados obstáculos à inserção da tecnologia, maiores que as de outras culturas e criações.

Palavras-chave: Inovação. Agricultura familiar. Segurança Alimentar. Desenvolvimento sustentável. Tecnologia apropriada.

148 - Título: DIAGNÓSTICO NO MUNICÍPIO DE SÃO JOSÉ DO POVO: MIGRAÇÕES, ASSENTAMENTOS, SEGURANÇA ALIMENTAR E OUTROSFATORES DE BASE PARA O DESENOLVIMENTO LOCAL

Nome: Elizabete Maria da Silva

Orientador: Profa. Dra. Marney Pascoli Cereda

Data da apresentação: $12 / 03 / 2010$

Resumo: A pesquisa surgiu da preocupação da pesquisadora com a questão de que a posse da terra deveria garantir a Segurança Alimentar da família. Entretanto apesar dos programas e projetos para garantir a auto - sustentabilidade, o meio rural continua a apresentar grande mobilidade por parte das famílias, em todos os níveis de propriedades, entre esses estão os jovens. Para responder a essas preocupações as ações de pesquisa foram implantadas tendo como base a sede do Município de São José do Povo e o Assentamento Padre Josimo Tavares, onde a pesquisadora desenvolve ações junto à comunidade buscando o bem estar e desenvolvimento sustentável. Os resultados obtidos foram divididos em cinco artigos, tendo como núcleo a sustentabilidade das comunidades no meio rural, enfocando a preocupação com o êxodo, principalmente dos jovens. O primeiro artigo, DESCRIÇÃO DO MUNICÍPIO DE SÃO JOSÉ DO POVO E 
DO ASSENTAMENTO PADRE JOSIMO TAVARES, caracteriza e compara o local e a comunidade com outras descrições da literatura com foco na sustentabilidade do município e do Assentamento, buscando verificar a sustentabilidade. As informações foram obtidas de documentos e diretamente da comunidade por entrevistas e questionários. Procurou-se contextualizar o município e o Assentamento quanto a Segurança Alimentar, Educação, Saúde e Lazer, bem como elencar as expectativas dos jovens moradores do município e das famílias moradoras do Assentamento. No segundo artigo, MIGRAÇÕES, POSSE DA TERRA E SEGURANÇA ALIMENTAR: ESTUDO DE CASO DO POVOAMENTO DO MUNICÍPIO DE SÃO JOSÉ DO POVO, MATO GROSSO, BRASIL, é abordada a polêmica distribuição de terras no Brasil. Entre os anos 40 e 50 muitos foram os movimentos migratórios no Brasil, sendo os mais relatados aqueles do Nordeste em direção as grandes cidades do Sudeste. O povoamento de São José do Povo, Município ao Sul do Estado do Mato Grosso, localizado na região Centro Oeste do país, foi uma das regiões que recebeu migrantes. Uma dessas migrações em particular se deu de Jampruca, Minas Gerais para a região onde hoje se encontra o município de São José do Povo, MT. A hipótese estabelecida foi de que essa migração se deu em razão da necessidade de garantir Segurança Alimentar, em seu conceito mais abrangente. A pesquisa partiu da experiência da pesquisadora responsável, cuja família tomou parte dessa migração. Para resgatar as informações necessárias foram usados documentos e informações diretas obtidas por entrevistas. Muitos dos entrevistados enfatizam os problemas enfrentados para acesso a alimentos por insuficiência de renda e terra no município de origem. Foi também constatado o uso inadequado dos recursos naturais que ao se exaurirem obrigaram os moradores a buscarem novas terras. A hipótese de que a Segurança Alimentar foi o eixo responsável pela migração da comunidade de Jampucra para São José do Povo foi confirmada, mas deixou em aberto a questão de porque uma vez de posse da terra as comunidades não atingem a necessária sustentabilidade. Desta pesquisa ficou claro que a questão do uso inadequado dos recursos naturais havia criado condições de insegurança alimentar no local de origem e que esse fenômeno poderia se reproduzir no novo local. A pesquisa mostrou também a importância da organização social para chegar a sustentabilidade. No artigo a CONTRIBUIÇÃO DA RELIGIÃO PARA COM O DESENVOLVIMENTO LOCAL: ESTUDO DE CASO DAS AÇÕES DA ORGANIZAÇÃO “DANDO AS MÃOS” foi dado ênfase na atuação das Irmãs Catequistas franciscanas, da Província Santa Teresa do Menino Jesus, junto aos assentados na região da Diocese de Rondonópolis, MT. Entre os assentamentos em que as Irmãs atuam, está o Assentamento Padre Josimo Tavares, um dos que constitui a "Dando as Mãos", Organização solidária dos assentados e Empreendedores em Geral, organização gestada e acompanhada pelas irmãs, na preocupação com as lutas políticas e compromisso com a transformação social. Apesar de ser notória a participação de alguns setores da Igreja Católica na luta pela terra, a metodologia usada para atender a comunidade ainda é uma questão em aberto. Em resposta a essa questão, as irmãs (assim como outros setores da Igreja), desde o final de 1999 vem desenvolvendo ações no sentido de se aproximar mais dos assentados e construir alternativas conjuntas para o desenvolvimento local. Para isso é necessário contar com a confiança da comunidade em uma ambiente de desestabilidade social das comunidades rurais, uma vez esgotada a ligação existente no início da luta pela terra. Os resultados identificaram as ações das irmãs como capazes de gerar confiança entre os participantes do projeto, o que pode se traduzir em mais sustentabilidade. Uma vez identificada a necessidade do "agente de desenvolvimento", no caso as Irmãs Catequistas franciscanas, se aproximar da comunidade para entender seus problemas, surgiu a preocupação da pesquisadora em relação a evasão do campo após haver conseguido, (a duras penas), a posse da terra.

\section{9 - Título: EMPODERAMENTO E POTENCIALIDADES PARA DESENVOLVIMENTO LOCAL NA TRADICIONAL COMUNIDADE NEGRA “SÃO JOÃO BATISTA” DE CAMPO GRANDE, MS}

Nome: Mônica Cristina Adams Matos da Silva

Orientador: Prof. Dr. Vicente Fideles de Ávila

Data da apresentação: 06/04/2010

Resumo: Intitulada Empoderamento e Potencialidades para Desenvolvimento Local na Tradicional Comunidade Negra "São João Batista" de Campo Grande, MS, esta pesquisa se inseriu no contexto de Desenvolvimento Local de uma comunidade que se autodefiniu como remanescente de quilombo, certificada pela Fundação Cultural Palmares, no ano de 2006. A autodefinição é importante para o fortalecimento dessa identidade remanescente de quilombo por meio da valorização da cultura, da expressão religiosa e do reconhecimento de direitos. A Comunidade Negra São João Batista, com aproximadamente 60 pessoas (15 famílias), reside em área urbana na cidade de Campo Grande, MS. O objetivo geral do trabalho foi conhecer as configurações identitárias de resistência da Comunidade Negra São João Batista e analisar suas potencialidades para o Desenvolvimento Local face aos referenciais da 
solidariedade comunitário-produtiva. A investigação pautou-se nos pressupostos da pesquisa qualitativodescritiva de inspiração etnográfica com a utilização dos instrumentais metodológicos: observação participante, relatos orais, entrevistas e registros fotográficos. A análise e sistematização dos resultados se pautaram pela análise de conteúdo. O referencial teórico utilizado baseou-se nos fundamentos do Desenvolvimento Local, uma vez que se entendeu ser esse o caminho possível para se responder às questões do trabalho. Para percorrer esse caminho procurou-se, também, contextualizar historicamente o período da escravidão no Brasil e em Mato Grosso do Sul. A partir do cotidiano dessa comunidade, tentou-se compreender os fenômenos que a compõem e as potencialidades para o seu desenvolvimento. Dentre os resultados obtidos, destaca-se a importância das manifestações culturais e religiosas e da sua organização sociopolítica para o fortalecimento de sua identidade como remanescente de quilombo e consequentemente para o seu desenvolvimento.

Palavras-chave: Desenvolvimento Local, Comunidade Tradicional, Identidade, Cultura, Empoderamento.

150 - Título: IMPACTOS DE UMA AÇÃO EDUCATIVA A DISTÂNCIA DO CURSO SUPERIOR DE TECNOLOGIA EM GESTÃO E MARKETING DE PEQUENAS E MÉDIAS EMPRESAS NO DESENVOLVIMENTO LOCAL, SOB A ÓTICA DA EDUCAÇÃO A DISTÂNCIA

Nome: Fabiana Annibal Faria de O. Biazetto

Orientador: Dra. Cleonice Alexandre Le Bourlegat

Data da apresentação: $12 / 08 / 2010$

Resumo: O objetivo deste trabalho foi analisar impactos de uma ação educativa a distância do Curso Superior de Tecnologia em Gestão e Marketing de Pequenas e Médias Empresas no desenvolvimento local, sob a ótica da educação a distância. O interesse inicial surgiu do entendimento de que os cursos a distância, sobretudo os de graduação, têm alcançado localidades ermas do território nacional, algumas delas sem saneamento, telefones ou asfalto. Trata-se de localidades que não oferecem educação de nível superior à população nativa. Nesse sentido, para desenvolver o presente trabalho, adotou-se uma abordagem quali e quantitativa acerca dos fundamentos de ensino a distância, do território constituído e do território vivido, destacando o desafio de relacionar essas variáveis com a construção de conhecimento e a consequente melhoria de vida dos alunos do curso. O estudo partiu, então, da abrangência desse curso no Brasil e das principais características socioeconômicas dos alunos e dos territórios atingidos, observando o processo de ensino/aprendizagem empreendido e a resultante na ampliação de capacidades, competências e habilidades dos alunos, no seu desenvolvimento profissional e no âmbito da melhoria da vida coletiva. Diante disso, a análise do trabalho recaiu, num primeiro momento, sobre os pressupostos que criaram o ensino a distância. Em seguida, aprofundou-se o conhecimento acerca dos diversos territórios envolvidos e suas particularidades. Analisou-se o período de janeiro de 2007 a agosto de 2009, tendo como foco os alunos do último semestre do Curso de Tecnologia em Gestão e Marketing de Pequenas e Médias Empresas, bem como os territórios envolvidos no processo de ensino/aprendizagem a distância. Com base no estudo realizado, é possível considerar a EAD como uma resposta a um dos grandes desafios na luta contra as desigualdades sociais, tendo em vista que possibilita mais acesso à informação, por meio das novas tecnologias de comunicação adotadas.

\section{1 - Título: O CENTRO QUE VEM ATÉ AQUI: UM ESTUDO HEURÍSTICO EM DESENVOLVIMENTO LOCAL}

Nome: Yan Leite Chaparro

Orientador: Dr. Josemar de Campos Maciel

Data da apresentação: 10/02/2010

Resumo: Este estudo constrói um espaço minucioso do diálogo, com o possível leitor que aceita o convite. A escuta é tema central, instante que traz indagações quando se pensa a representação do Outro na contenporaneidade, sua voz e sua posicionalidade como diferente, sendo eu e meu, se definido como e porque da própria existência como sujeito. Escuta que se fundamenta no encontro com o cotidiano, entre - casas, nas arrumações de problemas e suavidade densa do falso silêncio do lugar. Compondo um estudo Heurístico para a esfera social, compondo a partir da experiência as analises possíveis relacionadas às artimanhas cotidianas, junto à cerâmica. $O$ pesquisador se coloca como sujeito e objeto, exigindo da sua insegurança no lugar, composições que alimentam a constituição teórica proporcionada com todo o movimento da pesquisa, evidenciado em cada micro-narrativa e analise teórica.

Palavras-chave: Alteridade. Cotidiano. Artimanhas. Pós-estruturalismo. Desenvolvimento Local. 


\title{
152 - Título: OMUSEU DASCULTURASDOM BOSCO:HISTÓRIA,IDENTIDADEEPOTENCIALIDADES DE DESENVOLVIMENTO LOCAL NA EDUCAÇÃO BÁSICA
}

\author{
Nome: Rejiane Platero Ferreira \\ Orientador: $\operatorname{Dr}(\mathrm{a})$. Maria Augusta de Castilho \\ Data da apresentação: 30/06/2010
}

Resumo: Este trabalho sintetiza uma pesquisa que teve como eixo norteador verificar a interação existente entre as comunidades escolares e o Museu das Culturas Dom Bosco. Para a materialização das hipóteses levantadas, foram feitas reflexões sobre os conceitos de comunidade, território e territorialidade, identidade dentre outros. Utilizou-se como suporte referencial teorias desenvolvidas pelos estudiosos da disciplina de Desenvolvimento Local, uma vez que o Museu das Culturas Dom Bosco pode vir a ser um espaço com potencialidades para a consolidação do desenvolvimento local junto às comunidades escolares. O Museu, como espaço cultural e de produção de conhecimento, tem o dever de promover o desenvolvimento local frente às comunidades escolares, possibilitando a participação destas como gestoras de um processo capaz de apontar as possíveis deficiências do museu no tratamento de questões referentes ao aprendizado e as necessidades pedagógicas do público alvo, para que possam ser supridas, possibilitando a consolidação contínua e ininterrupta de aspectos do desenvolvimento local postos em evidência pela pesquisa.

Palavras-chave: Comunidades escolares. Desenvolvimento local. Museu das Culturas Dom Bosco.

153 - Título: PERCEPÇÃO DOS PECUARISTAS E AGRICULTORES DE GRÃOS EM RELAÇÃO AO SETOR SUCROALCOOLEIRO NO MUNICÍPIO DE DOURADOS/MS

\author{
Nome: Cláudia Marinho Carneiro Noda \\ Orientador: Prof. Dr. Luís Carlos Vinhas Ítalo
}

Data da apresentação: 29/03/2010

Resumo: Objetivou-se analisar a percepção dos pecuaristas e agricultores de grãos em relação ao setor sucroalcooleiro no município de Dourados/MS, sob a ótica de desenvolvimento local em contexto de territorialidades. A problemática do estudo se deu pela ampliação da cultura da cana-de-açúcar que favorece o desencadeamento de problemas de natureza social e econômica. O estudo caracterizou-se como uma pesquisa quali-quantitativa de caráter exploratório. Utilizou-se revisão bibliográfica e a coleta de dados foi realizada por meio de questionário e abordou questões qualitativas e quantitativas, aplicado em duas épocas distintas: novembro de 2008 e fevereiro de 2010, quando foram entrevistados 42 agropecuaristas, 09 trabalhadores rurais que trabalham em diferentes áreas do Agronegócio entre cana de açúcar, soja, milho e pecuária, 21 instituições do comércio local (comércio, serviços, instituição financeira e cooperativa). Para o incremento das informações relevantes, foram entrevistados representantes diretos da usina do município e também o co-presidente da Comissão Interamericana do Etanol. Os resultados apontam para a realidade do Agronegócio e dos atores envolvidos na produção de grãos e pecuária, assim demonstrando a percepção que a agropecuária mantém quanto à expansão do cultivo de cana-de-açúcar, indústria de açúcar, fabricação de etanol e co-ogeração de energia e seus impactos socioeconômicos no meio rural e urbano. Diante deste contexto, o emprego e a renda passam a ser fatores determinantes para o desenvolvimento econômico, sendo uma saída para estimular o desenvolvimento agroindustrial do município de Dourados e, por conseqüência, dar qualidade de vida e bem estar à sociedade local.

Palavras-chave: Desenvolvimento local. Agropecuária. Agronegócio. Impactos socioeconômicos

\section{4 - Título: PESPECTIVA DO TURISMO DE BASE COMUNITÁRIA COMO AGENTE DE INCLUSÃO SOCIAL: O CASO DO MUNICÍPIO DE BODOQUENA, MS}

Nome: Domingos Sávio de Souza Mariuba

Orientador: Dra. Reginaldo Brito da Costa

Data da apresentação: 02/08/2010

Resumo: O presente estudo objetivou detectar potencialidades turísticas naturais e culturais envolvendo comunidades no município de Bodoquena, Mato Grosso do Sul. Constatou-se que há número expressivo de pequenos estabelecimentos agropecuários. Se aproveitadas suas potencialidades naturais e culturais, com as pequenas comunidades da região, como é o caso em foco neste estudo, o resultado será de grande alcance, com o turismo sendo agente de inclusão social, e no sentimento de solidariedade da comunidade terá as bases necessárias para avanço do capital social. A consolidação da aliança entre comunidadegoverno torna-se importante para que esse avanço produza mudanças no aspecto cultural e na qualidade 
de vida, tendo na atividade econômica do turismo, fator de oportunidade para que a inclusão social aconteça. Os resultados encontrados serão estudados se, no município de Bodoquena, o segmento de Turismo de Base Comunitária, nos assentamentos e comunidades, poderá ser consolidado com base em desenvolvimento local, e os proprietários das pequenas propriedades serem capacitados para atender os turistas que para lá se deslocarem. Essas alternativas com as possibilidades de inovação mostram as forças das comunidades que vêm surgindo gradativamente como alternativa de desenvolvimento, a partir das melhorias concebidas no contexto do desenvolvimento local.

\section{5 - Título: REDE DE ECONOMIA SOLIDÁRIA E PAPEL DA MOEDA SOCIAL NO MUNICÍPIO DE DOURADOS, MATO GROSSO DO SUL}

Nome: Mariluce Fernandes

Orientador: Dra. Olivier François Vilpoux

Data da apresentação: 04/03/2010

Resumo: Atividades como costura, artesanato, panificação, fabricação de produtos de limpeza, prestação de serviços diversos como eletricista, encanador, pedreiro, são exercidas por empreendedores ligados a Rede de Economia Solidária de Dourados, Mato Grosso do Sul. A Rede de Economia Solidária contou com apoio da Secretaria de Assistência Social e Economia Solidária, até 2008, e do Banco Pirê, Banco Social cuja mantenedora é a ONG Mulheres em Movimento, que tem como prioridade fomentar a Rede de Economia Solidária de Dourados. O Banco Pirê lançou a moeda social Pirapirê, cujo uso é voluntário, não podendo ser depositado em bancos. Os serviços oferecidos pelo Banco Pirê são: finanças solidária, cartão de crédito PirêCred, apoio técnico, jurídico e financeiro na criação de micro empresas cooperadas da economia solidária, apoio à comercialização do produtos e serviços da Rede através da administração da Loja Solidária e formação cidadã aos produtores e consumidores. O objetivo da pesquisa foi analisar o funcionamento da Rede de economia solidária no município de Dourados, Mato Grosso do Sul, e verificar a importância da moeda social como ferramenta de fortalecimento dessa economia solidária. A partir dos resultados obtidos, concluiu-se que os empreendimentos não estão comprando matéria-prima em conjunto conforme a idéia implantada, mas estão caminhando para que estejam cada vez mais fortalecidos e encorajados para uma comercialização maior. Existe individualismo entre os empreendimentos com relação a compra e produção. A união entre eles existe somente quando há necessidade de nota fiscal para venda ou compra e, nos pontos de comercialização. Mesmo com o intuito de fazer circular entre os empreendedores da Rede seus produtos e serviços, a moeda social não esta sendo bem aceita. Há certo refugo. A Rede de Economia Solidária se esforça para implantar e aplicar os princípios da economia solidária em todos os empreendimentos nela inseridos, mas até o momento das entrevistas a rede era reconhecida principalmente por seu papel na formação dos empreendedores.

Palavras-chave: Economia Solidária. Moeda Social. Desenvolvimento Local.

\section{6 - Título: TRADIÇÃO, ARTESANATO DO CAPIM DOURADO E DESENVOLVIMENTO LOCAL NO POVOADO MUMBUCA DO JALAPÃO EM MATEIROS-TO}

Nome: Ruberval Rodrigues de Sousa

Orientador: Prof. Dr. Vicente Fideles de Ávila

Data da apresentação: 08/04/2010

Resumo: As comunidades tradicionais quando tomadas como objeto de estudo, nem sempre têm todos os seus aspectos levados em consideração. Este trabalho foi realizado em uma comunidade remanescente de quilombola situada no Jalapão, na região leste do Estado do Tocantins, visando identificar e analisar suas relações com o capim dourado, planta típica da região, utilizada para a confecção de artesanato e os seus potenciais de Desenvolvimento Local. Há aproximadamente um século os descendentes de escravos ocupam o mesmo local e atualmente vivem quase que exclusivamente da venda do artesanato de capim dourado, o qual tornou-se conhecido por várias partes do mundo. A tradição em torno do capim dourado é passada de pai para filho há várias gerações, entretanto, a comunidade não ganhou a mesma importância que o fruto do seu trabalho - o artesanato do capim dourado.

Palavras-chave: Desenvolvimento. Tradição. Capim Dourado. Artesanato. Povoado Mumbuca. 